recently been used by G. G. Lennon, of Bristol, to show the outlines of the foetus and its intestinal tract (unpublished). Later, radio-opaque dyes were put into the bladder and barium into the rectum to see if the foetal head was displaced from these two organs by a soft-tissue mass. This method was supplanted by soft-tissue radiography in which no radioopaque dyes were used, but the displacement of the head from the bony points of the symphysis and the sacral promontory were noted.' This can help with the diagnosis of placenta praevia, but showing the position of the placenta in the upper uterine segment is not so accurate except when there is calcification. ${ }^{2}$ Soft-tissue radiography is not of much value before about the 34th week of pregnancy, and, despite reports of success from the originators of the methods and enthusiasts, other workers with no special interest in obstetric radiology have found the results to be indifferent.

The injection of radio-opaque dyes into the arterial system, most often through a catheter introduced into the femoral artery, shows the placental site clearly at all stages of pregnancy. ${ }^{3}$ Injuries to the artery at the site of injection do occur but are not common. One difficulty in interpretation is defining the upper limit of the lower uterine segment, so that arbitrary bony points have to be selected as roughly defining the position of the junction of upper and lower uterine segments. A speculum in the vagina can indicate the site of the cervix.

Radiological methods all carry the potential danger of damage to the foetal gonads, and perhaps the same criticism may be levelled at the injection of isotopically labelled compounds such as radioiodinated serum albumin. The placental area can be found by the fact that the placental lake of blood shows a high degree of radioactivity. ${ }^{5}$ The radiation dosage is less than that used in conventional radiological techniques but the albumin method is still experimental.

Attempts to find the placenta by thermography ${ }^{6}$ are especially interesting because nothing is done which could cause any damage either to the mother or to her foetus. But the results are not yet accurate enough ${ }^{7}$ to warrant general use in clinical practice.

Recently ultrasonic techniques have been used to find the placenta. ${ }^{8}$ They have been found to be $97 \%$ accurate in 112 patients where the position of the placenta could be checked at operation or manual removal of the placenta. The virtues of ultrasonic diagnosis are that it causes no damage to either mother or foetus, it can be used at all stages of pregnancy, it can be repeated many times, and it can show the placental site wherever it may be in the uterus. There can be little doubt that the method should be more widely adopted, and not only for placental localization, for it has many other spheres of usefulness. In obstetrics the reasons for failure to use ultrasonics seem to be innate conservatism, the inevitable lack of money-though the apparatus is not extremely expensive-and indecision on who should house and use the apparatus. Radiologists would seem to be the logical people to cope with the new techniques, though there are many reasons why they may feel unable to do so, but it is to be hoped that more of them will try to find the space, money, and time to master the taking and reading of ultrasonographs.

Reid, F., Brit. 7. Radiol., 1949, 22, 557

Hartley, J. B., ibid., 1954, 27, 365

- Fernitröm. I., Acta radiol. (Ślockh), 1955, Suppl. No. 122

- Sutton. D., Brit. 3. Rudiol., 1966, 39, 47.

- Bru med. F., 1964. 2, 961 .

- Young. R. J., ibid., 1964, 2, 978.

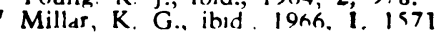

- Gottesteld K. R., Thompson. H. E., Holmes, J. H., and Taylor, E. S., Amer. 3. Obsiet. Gynec., 1966, 96, $\$ 38$.

\section{Human Growth Hormone}

In 1921 H. M. Evans and J. A. Long' reported that extracts of bovine anterior pituitary glands could promote growth. Subsequent investigations showed that the active principle not only caused the expected retention of nitrogen but also resulted in the mobilization of fat from the body depots and sometimes produced impairment of carbohydrate tolerance and even frank diabetes. ${ }^{2}$ Bovine growth hormone was finally isolated in $1945,^{3}$ but was later found to be ineffective in man. C. $\mathrm{H}$. $\mathrm{Li}$ and $\mathrm{H}$. Papkoff ${ }^{4}$ provided the explanation for this when they showed that human growth hormone was structurally different from bovine growth hormone.

Human growth hormone is now known to produce similar metabolic changes to those found in animals. ${ }^{5}$ It can be identified in the sera of people of all ages. ${ }^{78}$ It is therefore perhaps surprising that adults with hypopituitarism can be maintained in apparently good health by replacement therapy with cortisone, thyroxine, and sex hormones, and that they appear to show no specific effects of lack of growth hormone. But in children dwarfism is a prominent feature of a deficiency of growth hormone, and replacement therapy may be valuable in certain types of dwarfism.

The treatment of dwarfism depends on the cause of the condition. Thus arrest of growth due to hypothyroidism will respond to treatment with thyroxine. Hypopituitarism, whether idiopathic or secondary to some local lesion, is a well-known though unusual cause of dwarfism, which was found to be responsible for $6.7 \%$ of one group of patients. It might be expected that these patients would show an acceleration of growth after treatment with human growth hormone, and this has now been reported from several centres. $^{10} 11$ At p. 69 of this week's B.M.7. Professor J. M. Tanner and Mr. R. H. Whitehouse report on the results of long-term therapy with the hormone. Three of their patients had developed hypopituitarism after the removal of a craniopharyngioma, and all three responded well to treatment. The hormone is usually given two or three times a week by intramuscular injection, and this treatment has been maintained for several years without any harmful side-effects. Administration of the hormone has not usually stimulated sexual development or undue acceleration of bone maturation, though a disproportionate increase of bone age (as commonly

1 Evans, H. M., and Long, J. A., Anat. Rec., 1921, 21, 62.

2 De Bodo, R C.. and Altszuler, N., Vitam. and Horm., 1957, 15, 205.

- Li, C. H., Evans, H. M., and Simpson, M. E., f. biol. Chem., 1945, is9, 353 .

- Papkoff. H., Science, 1956, 124, 1293.

- Beck, J. C., McGarry, E. E., Dyrenfurth, I., and Venning, E. H., ibid. 1957, 125,884

- Clinical Endocrinology Committee of the Medical Research Council, Lancet, 1959. 1, 7.

- Gershberg, H., Endocrinology, 1957, 61, 160.

- Glik, S. M.. Roth, J., Ydow, R. S., and Berson, S. A., Nature (Lond.), 1963, 199. 784.

- Marun. M M., and Wilkins, L., \%. clin. Endocr., 1958, 18, 679.

10 Raben, M S., New Engl. J. Med., 1962, 266, 82.

"Snyka, L. F., Ziskind, A., and Crawford, J. D., ibid., 1964, 271, 754.

1. Prader, A., Ïllig, R., Széky, J., and Wagner, H., Arch. Dis. Childh., rader, A., Thig,

S Raben, M. S. Minton, P. R., Mitchell, M. L., and Juarez-Penalva, H. Protein Metabolism, p 121 , ed. F. Gross. Berlin.

14 Nadler, H. L., Neumann, L. L., and Gershberg, H., J. Pediat., 1963, 63, 977.

is Hutchings. J. J., Escamilla. R. F., Li. C. H., and Forsham, P. H., Amer 7. Dis. Childh. 1965. 109. 318.

16 Blodget, F. M., Burgin, L., Iezzoni, D., Gribetz, D., and Talbot, N. B., New Engl. 7 Med., 1956, 254, 636

1) Sova $F$ and Crawford I. D., Y. Pediat., 1964, 65, 1115.

11 . Lancet, $1964,2,376$

10 Roth, J., Gilick, S. M., Yalow, R. S., and Berson, S. A., Science, 1963, $140,987$.

20 Wright, C., Brasel, I A., Aceto, T., Finkelstein, J. W., Kenny, F. M., Spaulding, J. S., and Blizzard, R. M., Amer. J. Med., 1965, 38. 499. 
occurs with androgen therapy) did occur in the three youngest children studied by Tanner and Whitehouse. Antibodies to human growth hormone have been found in the scia of some patients receiving it, and they have sometimes been associated with a poor response to treatment. ${ }^{12}$

The treatment of patients with other types of dwarfism has usually not been so rewarding as the treatment of dwarfism due to hypopituitarism. Children in whom no specific cause for their short stature can be established have been termed "primordial" or "idiopathic" dwarfs, and probably the causes of their condition vary. Acceleration of growth in some of these patients by growth hormone has been reported, ${ }^{13}$ while in others the results have been disappointing. ${ }^{11}$ The existence of a state of isolated deficiency of growth hormone in the absence of deficiency of other anterior pit. itary hormones has been recorded, ${ }^{14}$ and Tanner and Whitehouse diagnosed this condition in 16 of their patients, 10 of whom responded well to treatment. The response of patients with gonadal dysgenesis to treatment has been poor, ${ }^{11}{ }^{13}$ though some acceleration of growth in two patients has been reported. ${ }^{15}$ Many workers hoped that therapy with growth hormone might provide a treatment for the dwarfism which is such a prominent feature of long-term treatment of children with corticosteroids, ${ }^{16}$ as these substances antagonize the action of growth hormone peripherally, ${ }^{17}$ as well as suppressing its release from the pituitary. ${ }^{18}$ Studying two such children, Tanner and Whitehouse found no response to growth-hormone therapy in one, and a slight acceleration of growth in the other.

In assessing children with dwarfism for possible treatment with growth hormone accurate diagnosis is essential. This has been greatly aided by the measurement of the levels of growth hormone in the serum, usually during an insulintolerance test, as hypoglycaemia has been shown to be a potent stimulus for the release of growth hormone. ${ }^{19}$ Measuremest of the metabolic response to a short course of growth hormone has been found ${ }^{12}$ to be a useful guide in predicting response to long-term therapy, though other workers have not found it helpful. ${ }^{20}$ As growth hormone is extracted from human pituitary glands, its supply is necessarily restricted. In Britain the Medical Research Council has arranged for the collection of pituitary glands with the co-operation of pathologists throughout the country. Nevertheless, there are still many patients who might be expected to benefit from treatment with growth hormone for whom there is no material available. It is therefore to be hoped that as many pathologists as possible will help in collecting the glands, and particulars of the collection procedure may be obtained from the M.R.C.

\section{Resuscitation and the Nurse}

The report in the Supplement (p. 15) of the latest meeting of the Joint Committee of the British Medical Association and the Royal College of Nursing illustrates the rapidly evolving role of the nurse in the changing medical scene. Within the memory of senior members of the profession student nurses were not expected to take the blood pressure or give intramuscular injections. Now they must understand intermittent positive-pressure respirators and cardiac monitors, apparently give intravenous injections, and even undertake the onerous responsibility of initiating treatment of cardiac arrest.

The young nurse asks herself three questions about resuscitation: Will I be equal to the task when I first have to perform it? On what patients should resuscitation be attempted ? Will the result be happy or distressing ? The first can be answered by providing effective first-aid equipment, prompt medical support, and above all by detailed and really practical teaching. It is useless to suggest that a patient in a hospital bed should be placed on the floor if a nurse unaided is incapable of getting a heavy patient there without injuring him.

The question of whom to resuscitate is the most difficult of the three. Nobody dies nowadays, said a group of student nurses ; they have cardiac arrest, and sometimes it is permanent. At opposite extremes the decision is easy. Sudden collapse of unknown cause and cardiac arrest during an acute illness or operation require energetic treatment. On the other hand, the close of a long life or an incurable illness should be allowed to occur peacefully. Between these two are many patients about whom a decision may be hard to reach, or fraught with emotion. If the nurse is left to make it for herself she may try resuscitation where no good result can be expected, and if on the other hand she is told not to perform it she may feel, however illogically, that this is equivalent to euthanasia.

As to the results of resuscitation, what most nurses fear is not that the attempt may be unavailing but that the patient may live with faculties grossly impaired. Because each nurses's personal experience of treating cardiac arrest is small, the numerical chances of complete-success are also small. Doctors in charge of resuscitation units who see many cases are rewarded by some successful results. They must see that nurses are told about them and so encouraged to be alert and prompt to begin resuscitation.

\section{Treatment of Haemophilia}

There are between 1,500 and 2,000 males with haemophilia in Great Britain. They lack a globulin factor in their plasma that is necessary for the normal coagulation of blood. The haemostatic mechanism is restored to normal by infusion of the missing factor, antihaemophilic globulin (A.H.G.), but the effect of the infusion is of short duration. Half the activity disappears from the plasma in 8 to 12 hours, and thus the management of all but the most minor haemorrhages requires the daily infusion of sufficient material to maintain a concentration of A.H.G. of at least 20 to $30 \%$ of the level found in normal people.

Not only does infused A.H.G. disappear rapidly from the recipient's blood but the A.H.G. in freshly drawn normal blood falls equally rapidly. Thus the preparation of material suitable for treating attacks of bleeding in haemophiliacs has presented formidable problems. Even the delay between bleeding a donor and finally freezing the plasma results in loss of almost half the A.H.G., and many preparations may lose most of their potency by the time they are required for use. In practice it often proved difficult to infuse a suffciently large volume of fresh plasma to obtain fully effective levels of A.H.G. in bleeding haemophiliacs, and though concentrates of human material have been prepared they have been scarce.

The management of haemophilia has been transformed by the observations of J. G. Pool and J. Robinson ${ }^{1}$ that A.H.G. in plasma comes out of solution, together with fibrinogen and other proteins, at low temperatures and can be separated from the rest of the plasma in this state. In practice fresh plasma 